\title{
A lung abscess caused by secondary syphilis - the utility of polymerase chain reaction techniques in transbronchial biopsy: a case report
}

\author{
Shinji Futami ${ }^{1}$, Takayuki Takimoto ${ }^{1,3^{*}}$, Futoshi Nakagami ${ }^{2}$, Shingo Satoh ${ }^{1}$, Masanari Hamaguchi ${ }^{1}$, \\ Muneyoshi Kuroyama ${ }^{1}$, Kotaro Miyake ${ }^{1}$, Shohei Koyama ${ }^{1}$, Kota Iwahori ${ }^{1}$, Haruhiko Hirata', Izumi Nagatomo ${ }^{1}$, \\ Yoshito Takeda', Hiroshi Kida ${ }^{1}$ and Atsushi Kumanogoh ${ }^{1}$
}

\begin{abstract}
Background: In Japan and other countries, the number of patients with syphilis is increasing year by year. Recently, the cases of the pulmonary involvement in patients with secondary syphilis have been reported. However, it is still undetermined how to obtain a desirable specimen for a diagnosis of the pulmonary involvement, and how to treat it if not cured.

Case presentation: A 34-year-old man presented with cough and swelling of the right inguinal nodes. A physical examination revealed erythematous papular rash over the palms, soles and abdomen. A $4 \mathrm{~cm}$ mass in the right lower lobe of the lung was detected on computed tomography. He was diagnosed as having secondary syphilis, because he was tested positive for the rapid plasma reagin and Treponema pallidum hemagglutination assay. Amoxycillin and probenecid were orally administered for 2 weeks. Subsequently, rash and serological markers were improved, however, the lung mass remained unchanged in size. Transbronchial biopsy (TBB) confirmed the pulmonary involvement of syphilis using polymerase chain reaction techniques (tpp47- and polA-PCR). Furthermore, following surgical resection revealed the lung mass to be an abscess.

Conclusions: To our knowledge, this is the first surgically treated case of a lung abscess caused by syphilis, which was diagnosed by PCR techniques in TBB. This report could propose a useful diagnostic method for the pulmonary involvement of syphilis.
\end{abstract}

Keywords: Secondary syphilis, Lung abscess, Polymerase chain reaction, Transbronchial biopsy, Surgical treatment, Case report

\section{Background}

Syphilis is a sexually transmitted disease caused by infection with Treponema pallidum, which is classified into four stages (primary, secondary, latent and tertiary). If the patients with primary syphilis do not receive treatment, the bacterium will spread through their

\footnotetext{
* Correspondence: takimoto@imed3.med.osaka-u.ac.jp

${ }^{1}$ Department of Respiratory Medicine and Clinical Immunology, Osaka University Graduate School of Medicine, 2-2 Yamada-oka, Suita, Osaka 565-0871, Japan

${ }^{3}$ Department of Internal Medicine, National Hospital Organization, Kinki-Chuo Chest Medical Center, Sakai, Osaka, Japan

Full list of author information is available at the end of the article
}

bloodstream, and set the stage for secondary syphilis. Syphilis can cause a wide range of systemic manifestations, such as papular rash, malaise, weight loss, muscle aches, generalized lymphadenopathy and meningitis [1]. In Japan and other countries, the number of patients with syphilis is increasing year by year [2-4]. Recently, several dozen reports showed the pulmonary involvement in patients with secondary syphilis [5-16]; however, it is still undetermined how to obtain a desirable specimen for a diagnosis of the pulmonary involvement, and how to treat it if not cured.

(c) The Author(s). 2019 Open Access This article is distributed under the terms of the Creative Commons Attribution 4.0 International License (http://creativecommons.org/licenses/by/4.0/), which permits unrestricted use, distribution, and reproduction in any medium, provided you give appropriate credit to the original author(s) and the source, provide a link to the Creative Commons license, and indicate if changes were made. The Creative Commons Public Domain Dedication waiver (http://creativecommons.org/publicdomain/zero/1.0/) applies to the data made available in this article, unless otherwise stated. 


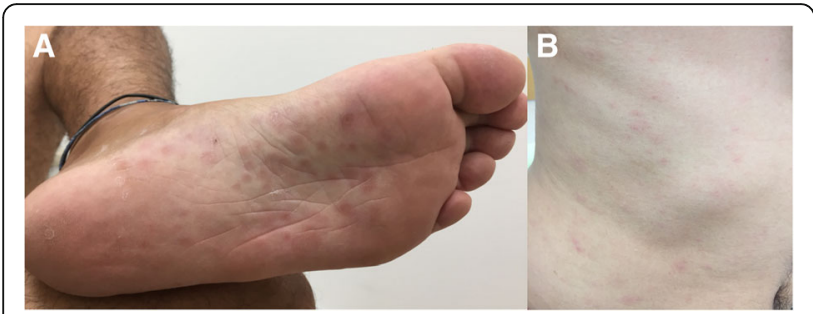

Fig. 1 Erythematous popular rash. a: Erythematous popular rash over the solesm, b: Erythematous popular rash over the abdomen

Table 1 Laboratory findings on the first visit to our institution

\begin{tabular}{|c|c|}
\hline \multicolumn{2}{|l|}{$<$ Blood cell count $>$} \\
\hline White blood cell & $7,150 / \mu \mathrm{L}$ \\
\hline Red blood cell & $520 \times 10^{4} / \mu \mathrm{L}$ \\
\hline Hemoglobin & $14.8 \mathrm{~g} / \mathrm{dL}$ \\
\hline Platelet & $27.8 \times 10^{4} / \mu \mathrm{L}$ \\
\hline \multicolumn{2}{|l|}{$<$ Serum chemistry $>$} \\
\hline Total protein & $8.1 \mathrm{~g} / \mathrm{dL}$ \\
\hline Albumin & $4.6 \mathrm{~g} / \mathrm{dL}$ \\
\hline Total-bilirubin & $0.5 \mathrm{mg} / \mathrm{dL}$ \\
\hline Alkaline phosphatase & $252 I U / L$ \\
\hline Aspartate transaminase & $15 \mathrm{IU} / \mathrm{L}$ \\
\hline Alanine transaminase & $23 I U / L$ \\
\hline$\gamma$-Glutamyl transpeptidase & $30 \mathrm{IU} / \mathrm{L}$ \\
\hline Lactate dehydrogenase & $158 \mathrm{IU} / \mathrm{L}$ \\
\hline Blood urea nitrogen & $11 \mathrm{mg} / \mathrm{dL}$ \\
\hline Creatinine & $0.84 \mathrm{mg} / \mathrm{dL}$ \\
\hline C-reactive protein & $1.02 \mathrm{mg} / \mathrm{dL}$ \\
\hline Sodium & $141 \mathrm{mmol} / \mathrm{L}$ \\
\hline Potassium & $4.4 \mathrm{mmol} / \mathrm{L}$ \\
\hline Chlorine & $103 \mathrm{mmol} / \mathrm{L}$ \\
\hline \multicolumn{2}{|l|}{$<$ Coagulation $>$} \\
\hline Prothrombin time (International normalized ratio) & 1.09 \\
\hline Activated partial thromboplastin time & $50 \mathrm{~s}$ \\
\hline \multicolumn{2}{|l|}{$<$ Infection $>$} \\
\hline Rapid plasma reagin test & Positive (titers 1:64) \\
\hline Treponema pallidum hemagglutination test & Positive (titers 1:5,120) \\
\hline Hepatitis B surface antigen & Negative \\
\hline Hepatitis C antibody & Negative \\
\hline Human immunodeficiency virus antibody & Negative \\
\hline Aspergillus antigen & Negative \\
\hline Cryptococcus antigen & Negative \\
\hline \multicolumn{2}{|l|}{$<$ Tumor marker $>$} \\
\hline Carcinoembryonic antigen & $<1 \mathrm{ng} / \mathrm{mL}$ \\
\hline Soluble cytokeratin fragment & $0.5 \mathrm{ng} / \mathrm{mL}$ \\
\hline Pro-gastrin releasing peptide & $27.0 \mathrm{pg} / \mathrm{mL}$ \\
\hline \multicolumn{2}{|l|}{$<$ Autoantibody> } \\
\hline Proteinase3-antineutrophil cytoplasmic antibody & $<1 \mathrm{U} / \mathrm{mL}$ \\
\hline Myeroperoxidase-antineutrophil cytoplasmic antibody & $<1 \mathrm{U} / \mathrm{mL}$ \\
\hline
\end{tabular}

Here, we report a rare case of a lung abscess caused by secondary syphilis, that was definitely diagnosed by polymerase chain reaction (PCR) tests from the transbronchial biopsy (TBB) specimen and followed by surgery.

\section{Case presentation}

A 34-year-old Japanese heterosexual man presented to our hospital with a $4 \mathrm{~cm}$ heterogeneous mass in the right lower lobe (Fig. 2). He had had a symptom of productive coughing, sore throat and nasal discharge for 5 days, but he had no fever and no dyspnea, and his general condition was good. He had a medical history of minimal lesion nephrotic syndrome and had received corticosteroid therapy until 4 months prior to his first visit to our institution. He was a current smoker (15 pack-years). He had had sexual intercourse with a woman other than his wife 4 months prior to his first visit. Physical examination revealed right inguinal nontender enlarged lymph nodes, and erythematous papular rash over the palms, soles and abdomen (Fig. 1). However, cervical and supraclavicular lymph nodes were not palpable, and he did not have abnormal neurologic findings.

C-reactive protein level was elevated at $1.02 \mathrm{mg} / \mathrm{dL}$ as shown in the laboratory tests (Table 1). The rapid plasma reagin (RPR) and Treponema pallidum hemagglutination test (TPHA) revealed titers 1:64 and 1:5,120, respectively, although Human immunodeficiency virus testing was negative. Chest X-ray (Fig. 2a) and computed tomography (Fig. $2 \mathrm{~b})$ revealed a single mass lesion $(4 \mathrm{~cm}$ in size) in the right lower lobe, and enlarged lymph nodes $(4.5 \mathrm{~cm}$ in size) in the right inguinal region.

Diagnosed as secondary syphilis, amoxycillin $1500 \mathrm{mg}$ per day and probenecid $1000 \mathrm{mg}$ per day were orally administered for 2 weeks. Subsequently, rash, inguinal lymph nodes and serological markers were improved (Fig. 3), however, the lung mass remained unchanged in size (Fig. 2c). TBB confirmed the pulmonary involvement of syphilis by PCR techniques (tpp47-, and polA-

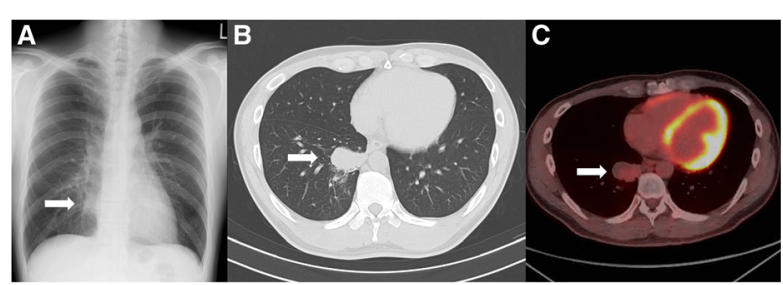

Fig. 2 Images of the lung mass. a Chest $X$-ray on the first visit to our hospital. A mass lesion was shown in the right lower field (arrow), $\mathbf{b}$ Chest computed tomography on the first visit to our hospital. A single mass lesion ( $4 \mathrm{~cm}$ in size) was shown in the right lower lobe of the lung (arrow), c Fluorodeoxyglucose-positron emission tomography (FDG-PET) before the surgery, 4 months after the first visit. A single mass lesion was still remained in spite of the antibiotic treatment. It had abnormal uptake with a maximal standardized uptake value (SUV max) of 2.51 (arrow) 


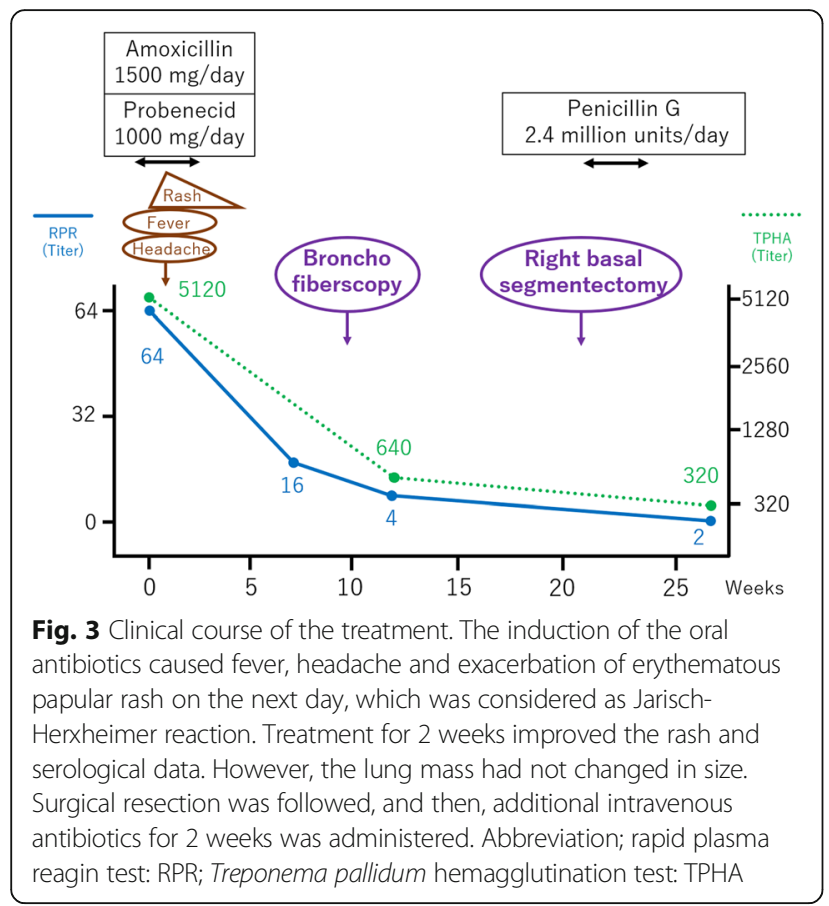

PCR) (Fig. 4), whereas malignancy and other possible infections such as bacteria and fungi were negative (Table 2). Five months after the first visit, right basal segmentectomy was performed to exclude other comorbid diseases, especially malignancy. The remained lung mass was an abscess and histological analysis showed the granuloma formation by epithelioid histiocytes and Langhans giant cells with necrosis (Fig. 5). The comprehensive PCR tests for multi-microbes were performed in the resected lung specimens, and no microbes were significantly positive (Table 2). Subsequently, penicillin G 2.4 million units per day was intravenously administered for 2 weeks, and the pulmonary involvement has resolved without relapse after 8 months follow-up.

\section{Discussion and conclusions}

This is a rare case of a lung abscess caused by secondary syphilis, that was diagnosed by PCR techniques in TBB. The abscess was not improved by antibiotics and required surgery.

Coleman showed the criteria for the clinical diagnosis of secondary syphilis with pulmonary involvement in 1983 [5], and several dozen cases have been reported [6-16]. In some of them, PCR was used for the diagnosis of pulmonary involvement (Table 3) [13-16]. PCR is useful for the diagnosis of the infection of Treponema pallidum $[18,19]$, because it is difficult to directly visualize Treponema pallidum. In those reports, PCR was used in samples from TBB, bronchoalveolar lavage (BAL), bronchial aspirate, or computed tomography-guided percutaneous needle aspiration (CTNA) [13-16]. Thus far, only one case has been reported on lung abscess caused by secondary syphilis, that was diagnosed by PCR in CTNA [15]. In our case, the results of PCR in samples from TBB, but not BAL, was positive. For the detection of some infectious diseases, TBB or the combination of BAL and TBB was reported to be useful [20,21]. Thus, it could be important to perform TBB to detect the pulmonary involvement by Treponema pallidum.

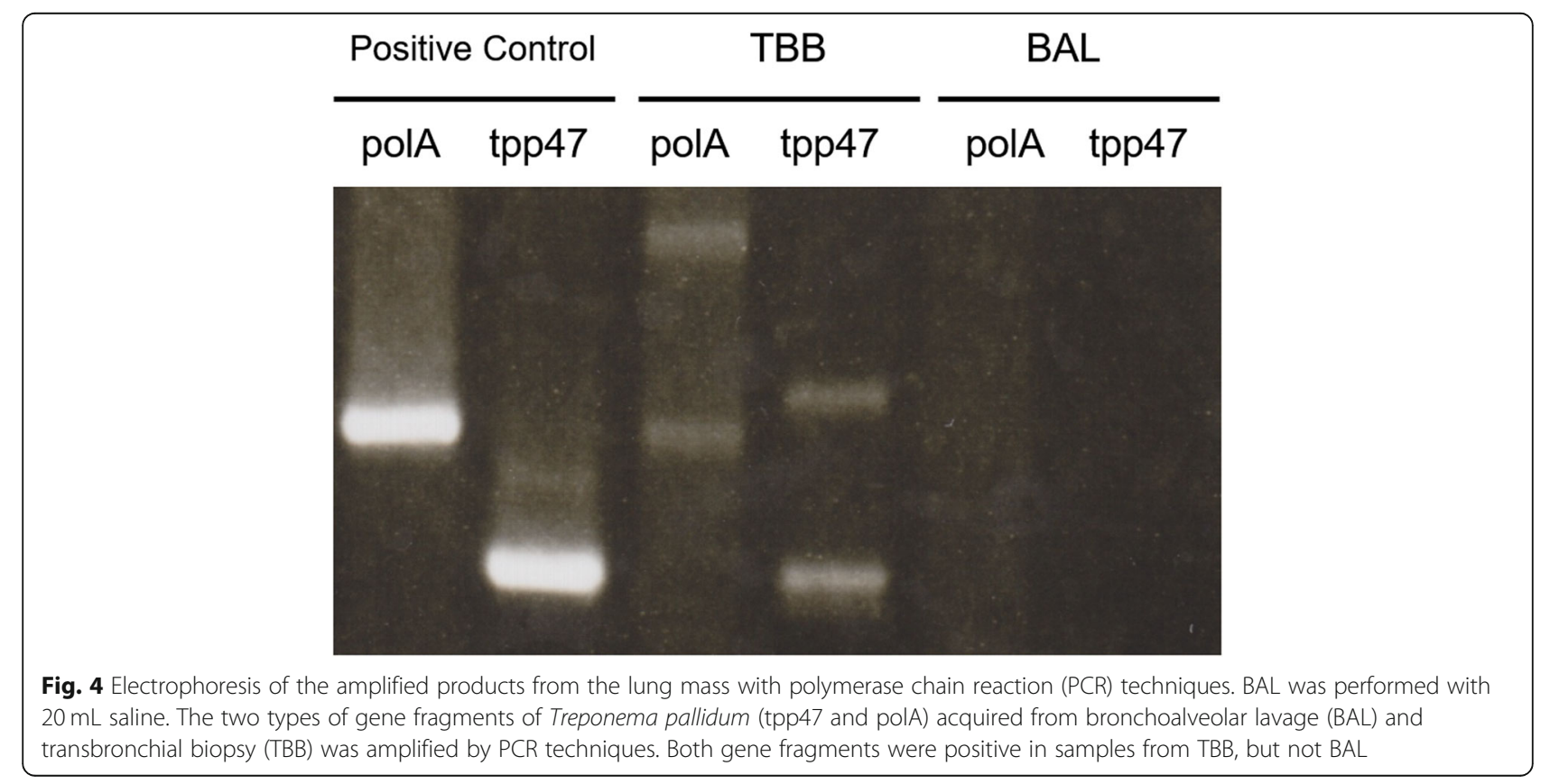


Table 2 Microbiological analysis in specimens obtained by bronchofiberscopy and surgery

\begin{tabular}{|c|c|}
\hline \multicolumn{2}{|c|}{ 1. Bronchofiberscopy } \\
\hline \multicolumn{2}{|c|}{ PCR tests for Treponema pallidum } \\
\hline \multicolumn{2}{|c|}{ Bronchoalveolar lavage } \\
\hline \multicolumn{2}{|l|}{ TBB } \\
\hline \multicolumn{2}{|c|}{ Culture tests for bacteria and mycobacteria } \\
\hline \multicolumn{2}{|c|}{ Bronchoalveolar lavage } \\
\hline \multicolumn{2}{|c|}{ Lavage of forceps in TBB } \\
\hline \multicolumn{2}{|c|}{ 2. Surgery } \\
\hline \multicolumn{2}{|c|}{ Real-time PCR tests for Treponema pallidum } \\
\hline \multicolumn{2}{|c|}{$\begin{array}{l}\text { Culture test for bacteria in pus inside the } \\
\text { abscess }\end{array}$} \\
\hline \multicolumn{2}{|c|}{ Real-time PCR tests for multi-microbes [17] } \\
\hline Number & Bacteria name \\
\hline 1 & Staphylococcus aureus \\
\hline 2 & Bacillus anthracis \\
\hline 3 & Listeria monocytogenes \\
\hline 4 & Streptococcus pyogenes \\
\hline 5 & Streptococcus agalactiae \\
\hline 6 & Streptococcus mutans \\
\hline 7 & Streptococcus sobrinus \\
\hline 8 & Streptococcus sanguinis \\
\hline 9 & Streptococcus oralis \\
\hline 10 & Streptococcus salivaris \\
\hline 11 & Streptococcus pneumoniae \\
\hline 12 & Enterococcus faecalis \\
\hline 13 & Enterococcus faecium \\
\hline 14 & Clostridium tetani \\
\hline 15 & Clostridium difficile \\
\hline 16 & Peptostreptococcus anaerobius \\
\hline 17 & Actinomyces \\
\hline 18 & Corynebacterium diphtheriae \\
\hline 19 & Mycobacterium tuberculosis \\
\hline 20 & Mycobacterium laprae \\
\hline 21 & Mycobacterium chelonae \\
\hline 22 & Mycobacterium kansasii \\
\hline 23 & Mycobacterium avium complex \\
\hline 24 & Nocardia asteroids \\
\hline 25 & Bacteroides fragills \\
\hline 26 & Elizabethkingia meningosepticum \\
\hline 27 & Campylobacter jejuni \\
\hline 28 & Helicobacter cinaedi \\
\hline 29 & Helicobacter pylori \\
\hline 30 & Rickettsia prowazekii \\
\hline 31 & Rickettsia japonica \\
\hline 32 & Orientia tsutsugamushi \\
\hline
\end{tabular}

Table 2 Microbiological analysis in specimens obtained by bronchofiberscopy and surgery (Continued)

\begin{tabular}{|c|c|c|}
\hline 33 & Bartonella henselae & Undetected \\
\hline 34 & Brucella & Undetected \\
\hline 35 & Bordetella pertussis & Undetected \\
\hline 36 & Burkhoderia mallei & Undetected \\
\hline 37 & Burkhoderia cepacian & Undetected \\
\hline 38 & Neisseria gonorrhoeae & Undetected \\
\hline 39 & Neisseria meningitidis & Undetected \\
\hline 40 & Francisella tularensis & Undetected \\
\hline 41 & Legionella pneumophilia & Undetected \\
\hline 42 & Moraxella catarrhalis & Undetected \\
\hline 43 & Pseudomonas aeruginosa & Undetected \\
\hline 44 & Acinetobacter baumannii & Undetected \\
\hline 45 & Aeromonas hydrophia & Undetected \\
\hline 46 & Vibrio cholerae & Undetected \\
\hline 47 & Vibrio parahaemolyticus & Undetected \\
\hline 48 & Vibrio vulnificus & Undetected \\
\hline 49 & Haemophilus influenzae & Undetected \\
\hline 50 & Escherichia coli & Undetected \\
\hline 51 & Salmonella enterica & Undetected \\
\hline 52 & Shigella & Undetected \\
\hline 53 & Klebsiella pneumonia & Undetected \\
\hline 54 & Yersinia psttis & Undetected \\
\hline 55 & Yersinia enterocolitica & Undetected \\
\hline 56 & Citrobacter freundii & Undetected \\
\hline 57 & Proteus mirabilis & Undetected \\
\hline 58 & Morganella morganii & Undetected \\
\hline 59 & Providencia & Undetected \\
\hline 60 & Mycoplasma pneumoniae & Undetected \\
\hline 61 & Fusobacterium nucleatum & Undetected \\
\hline 62 & Leptospira interrogans & Undetected \\
\hline 63 & Chlamydia psittaci & Undetected \\
\hline 64 & Chlamydia trachomatis & Undetected \\
\hline 65 & Chlamydia pneumoniae & Undetected \\
\hline 66 & Aspergillus fumigatus & Undetected \\
\hline 67 & Aspergillus nigar & Undetected \\
\hline 68 & Aspergillus flavus & Undetected \\
\hline 69 & Cryptococcus & Undetected \\
\hline 70 & Histoplasma & Undetected \\
\hline 71 & Trichosporon & Undetected \\
\hline 72 & Mucor & Undetected \\
\hline 73 & Coccidioides & Undetected \\
\hline 74 & Propionibacterium acnes & Detected (not significant) \\
\hline 75 & Stenotrophomonas maltophilia & Detected (not significant) \\
\hline 76 & Candida albicans & Detected (not significant) \\
\hline
\end{tabular}




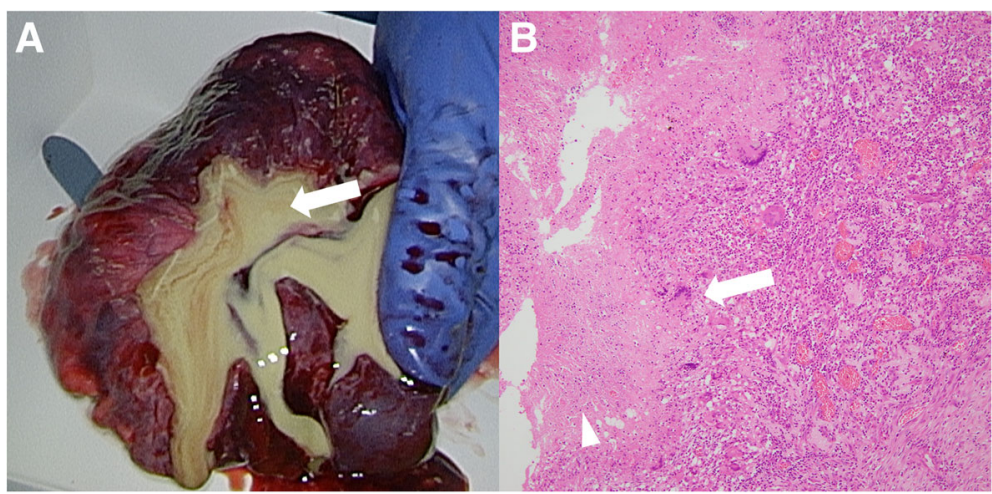

Fig. 5 Gross and microscopic pathology of lung specimens obtained by surgery a Gross pathology showed pus inside the lung abscess (arrow), b Microscopic pathology showed granuloma formation by epithelioid histiocytes and Langhans giant cells (arrow), in addition to necrosis (arrowhead). Original Magnification X100. Hematoxylin and eosin (HE) staining

Table 3 Reported cases of secondary syphilis with pulmonary involvement which was diagnosed by PCR techniques

\begin{tabular}{|c|c|c|c|c|c|c|c|c|}
\hline $\begin{array}{l}\text { Case } \\
\text { no. }\end{array}$ & Age & Gender & $\begin{array}{l}\text { Respiratory } \\
\text { symptoms }\end{array}$ & Extrapulmonary symptoms & Chest imaging & $\begin{array}{l}\text { Sample collection } \\
\text { method }\end{array}$ & $\begin{array}{l}\text { Reporting } \\
\text { year }\end{array}$ & Reference \\
\hline$\overline{1}$ & 34 & Male & Chest pain & $\begin{array}{l}\text { Progressive weakening, } \\
\text { anorexia, weight loss, and } \\
\text { night sweats }\end{array}$ & $\begin{array}{l}\text { Several bilateral, round, excavated } \\
\text { opacities and subtracheal } \\
\text { adenopathy }\end{array}$ & BAL & 2006 & [13] \\
\hline 2 & 49 & Female & Dry cough & $\begin{array}{l}\text { Disabling cervical pain, fever, } \\
\text { and night sweats }\end{array}$ & Lung lobe parenchymal lesion & $\begin{array}{l}\text { BAL and } \\
\text { bronchial aspirate }\end{array}$ & 2015 & [14] \\
\hline 3 & 30 & Male & $\begin{array}{l}\text { Hemoptysis, } \\
\text { chest pain, } \\
\text { dyspnea }\end{array}$ & Fever and rash & $\begin{array}{l}\text { a } 3 \mathrm{~cm} \text {, irregularly-shaped, well- } \\
\text { defined consolidation and a } 1 \mathrm{~cm} \\
\text { hilar node }\end{array}$ & CTNA & 2018 & [15] \\
\hline 4 & 62 & Male & $\begin{array}{l}\text { No respiratory } \\
\text { symptoms }\end{array}$ & epigastric pain & $\begin{array}{l}\text { Multiple nodular bibasilar } \\
\text { subpleural nodules }\end{array}$ & TBB & 2018 & [16] \\
\hline
\end{tabular}

Abbreviation: $P C R$ Polymerase chain reaction, BAL Bronchoalveolar lavage, CTNA Computed tomography-guided percutaneous needle aspiration, TBB Transbronchial biopsy 
The lung abscess was not improved by 2 weeks of oral antibiotics. It may be because penetration of antibiotics into the abscess was impaired. We treated the present case with amoxicillin and probenecid, because there is no insurance coverage for intramuscular penicillin for syphilis in Japan. Administration of intravenous penicillin $\mathrm{G}$ was considered as a more potent antibiotic treatment. However, as in this case, it is necessary to consider surgical resection as the treatment for uncontrolled infection and in order to exclude other diseases, including malignancy, when the lung involvement is poorly improved by antibiotics.

Lung lesions associated with syphilis are still rare, but the reported cases have been increasing as the number of patients with syphilis increases [5-16]. Thus, we should consider chest X-ray in the cases of the patients with syphilis who have pulmonary symptoms.

In conclusion, to our knowledge, this is the first surgically treated case of a lung abscess caused by syphilis, which was diagnosed by PCR techniques in TBB. This report could propose a useful diagnostic method for the pulmonary involvement of syphilis.

\section{Abbreviations}

BAL: Bronchoalveolar lavage; CTNA: Computed tomography-guided percutaneous needle aspiration; PCR: Polymerase chain reaction; RPR: Rapid plasma reagin test; TBB: Transbronchial biopsy; TPHA: Treponema pallidum hemagglutination test

\section{Acknowledgments}

The authors thank Shu-Ichi Nakayama, Makoto Ohnishi (Department of Bacteriology I), and Harutaka Katano (Department of Pathology, National Institute of Infectious Diseases, Tokyo, Japan), for their assistance with the PCR techniques. The authors obtained patient permission to publish this information.

\section{Authors' contributions}

SF and TT drafted the manuscript. SF, TT and FN were responsible for the clinical care of the patient. SS, MH, MK and KM contributed to the acquisition of the TBB specimen. SK, KI, HH and IN analyzed and interpreted the patient's data, including the microbiology data. YT, HK and AK critically revised the manuscript. All authors read and approved the final manuscript.

\section{Funding}

Not applicable.

\section{Availability of data and materials}

Not applicable.

Ethics approval and consent to participate

Not applicable.

\section{Consent for publication}

Written informed consent was obtained from the patient for publication of this case report.

\section{Competing interests}

The authors declare that they have no competing interests.

\section{Author details}

'Department of Respiratory Medicine and Clinical Immunology, Osaka University Graduate School of Medicine, 2-2 Yamada-oka, Suita, Osaka 565-0871, Japan. ${ }^{2}$ Department of General Internal Medicine, Osaka University Hospital, Suita, Osaka, Japan. ${ }^{3}$ Department of Internal Medicine, National Hospital Organization, Kinki-Chuo Chest Medical Center, Sakai, Osaka, Japan.
Received: 20 March 2019 Accepted: 30 June 2019

Published online: 09 July 2019

\section{References}

1. Ho EL, Lukehart SA. Syphilis: using modern approaches to understand an old disease. J Clin Invest. 2011;121(12):4584-92.

2. Sugishita Y, Yamagishi T, Arima Y, Hori N, Seki N. Increase in primary and secondary syphilis notifications in men in Tokyo, 2007-2013. Jpn J Infect Dis. 2016;69(2):154-7.

3. Patton ME, Su JR, Nelson R, Weinstock H. Centers for Disease Control and Prevention (CDC). Primary and secondary syphilis--United States, 2005-2013. Morb Mortal Wkly Rep. 2014;63(18):402-6.

4. Bremer V, Marcus U, Hamouda O. Syphilis on the rise again in Germany results from surveillance data for 2011. Euro Surveill. 2012;17(29).

5. Coleman DL, McPhee SJ, Ross TF, Naughton JL. Secondary syphilis with pulmonary involvement. West J Med. 1983;138(6):875-8.

6. Dooley DP, Tomski S. Syphilitic pneumonitis in an HIV-infected patient. Chest. 1994;105(2):629-31.

7. Zaharopoulos P, Wong J. Cytologic diagnosis of syphilitic pleuritis: a case report. Diagn Cytopathol. 1997;16(1):35-8.

8. Olson AL, Gutman JA, Welsh CH. A 50-year-old man with skin lesions and multiple pulmonary nodules. Chest. 2004;125(6):2322-7.

9. Alrajab S, Payne K, Areno J, Holladay R, Smith T, Zhang S. A 40-year-old man with a nodular lung disease and skin rash. Chest. 2012;141(6):1611-7.

10. Jeny F, Fargelat A, Laurent-Roussel $\mathrm{S}$, et al. Pulmonary consolidations due to secondary syphilis with positive bronchial washing immunohistochemistry. Am J Respir Crit Care Med. 2016;193(9):1061-2.

11. Ohta A, Furusyo N, Kishihara Y, et al. Secondary syphilis with pulmonary involvement. Intern Med. 2018;57(1):121-6.

12. Freitas DMM, Azevedo A, Pinheiro G, Ribeiro R. Psoriasiform papules, condyloma lata, lung nodules and hepatitis: the enormous variability of secondary syphilis manifestations. BMJ Case Rep. https://doi.org/10.1136/ bcr-2017-219408.

13. David G, Perpoint T, Boibieux A, et al. Secondary pulmonary syphilis: report of a likely case and literature review. Clin Infect Dis. 2006;42(3):e11-5.

14. Crouzy F, Alvarez V, Gex G, Troillet N. Unusual presentations and pitfalls of secondary syphilis: osteitis, pneumonia and malignancy. BMJ Case Rep. 2015. https://doi.org/10.1136/bcr-2015-210618

15. Visuttichaikit S, Suwantarat N, Apisarnthanarak A, Damronglerd P. A case of secondary syphilis with pulmonary involvement and review of the literature. Int J STD AIDS. 2018;29(10):1027-32. https://doi.org/10.1177/ 0956462418765834

16. Ogawa Y, Imai $Y$, Yoshihara S, et al. Pulmonary involvement of secondary syphilis. Int J STD AIDS. 2018;29(1):89-91.

17. Fukumoto H, Sato $\mathrm{Y}$, Hasegawa $H$, Saeki H, Katano H. Development of a new real-time PCR system for simultaneous detection of bacteria and fungi in pathological samples. Int J Clin Exp Pathol. 2015;8(11):15479-88.

18. Liu H, Rodes B, Chen CY, Steiner B. New tests for syphilis: rational design of a PCR method for detection of Treponema pallidum in clinical specimens using unique regions of the DNA polymerase I gene. J Clin Microbiol. 2001; 39(5):1941-6.

19. Orle KA, Gates CA, Martin DH, Body BA, Weiss JB. Simultaneous PCR detection of Haemophilus ducreyi, Treponema pallidum, and herpes simplex virus types 1 and 2 from genital ulcers. J Clin Microbiol. 1996;34(1): 49-54.

20. Sánchez-Cabral O, Martínez-Mendoza D, Flores-Bello ÁP, et al. Diagnostic discrepancy between bronchoalveolar lavage and transbronchial biopsy from bronchoscopies of HIV patients with pneumonia: toward an integral diagnosis. HIV AIDS (Auckl). 2018;10:115-23.

21. Broaddus C, Dake MD, Stulbarg MS, et al. Bronchoalveolar lavage and transbronchial biopsy for the diagnosis of pulmonary infections in the acquired immunodeficiency syndrome. Ann Intern Med. 1985;102(6):747-52.

\section{Publisher's Note}

Springer Nature remains neutral with regard to jurisdictional claims in published maps and institutional affiliations. 